\title{
Conservative Spine Care Pathway Implementation Is Associated with Reduced Health Care Expenditures in a Controlled, Before-After Observational Study
}

\author{
William B. Weeks, MD, PhD, MBA' , Jason Pike, $P h D^{2}$, Jeremy Donath, $B S^{2}$, Paul Fiacco, $M D^{3}$, and \\ Brian D. Justice, $D C^{2}$
}

${ }^{1}$ The Dartmouth Institute for Health Policy and Clinical Practice, Lebanon, NH, USA; ${ }^{2}$ Excellus BlueCross BlueShield, Rochester, NY, USA; ${ }^{3}$ Central New York Family Care, Syracuse, NY, USA.

KEY WORDS: back pain; health care costs; practice guidelines; value.

J Gen Intern Med 34(8):1381-2

DOI: $10.1007 / \mathrm{s} 11606-019-04942-7$

(๑) Society of General Internal Medicine 2019

\section{INTRODUCTION}

In the US, spine pain treatment is expensive and has uncertain outcomes. ${ }^{1}$ To reduce waste and improve patient outcomes, organizations like the American College of Physicians ${ }^{2}$ and Choosing Wisely (in concert with Consumer Reports) ${ }^{3}$ have published conservative spine care treatment recommendations.

As part of an effort to improve the clinical effectiveness and value of spine care, on March 1, 2015, Excellus BlueCross BlueShield (Excellus), headquartered in Rochester, NY, introduced a spine care pathway that incorporated conservative spine care recommendations in 1 primary care practice (with 11 primary care physicians (PCPs)) within an Excellus Accountable Cost and Quality Arrangement (a reimbursement model similar to an Accountable Care Organization) but not in another (with 74 PCPs). We sought to analyze the impact of the pathway's implementation by comparing expenditures for spine pain care in those practices.

\section{METHODS}

We obtained data on patients who were attributed to either primary care practice at any time between 4/1/14-3/31/18. Using ICD-9 or ICD-10 codes to identify spine pain patients, we treated any expenditure on spine pain care as an event. Each year, for each site, we calculated per-member-per-month (PMPM) spine care costs in 4 categories (all spine care, spine surgery care, opioid care, and manual care (physical therapy or chiropractic spinal manipulation)) for each attributed patient. We calculated PMPM expenditures for each cost category in each of the 3 years following initiation of the intervention and used a difference-in-difference approach to calculate the relative change from baseline (the year before intervention) to the 3 rd year following intervention. To generate time-group interaction estimates for each spine care cost category, we used a

Published online March 18, 2019 longitudinal Poisson model that accounted for repeated measures within each group over time, included 4 annual periods for each group, and used PMPM expenditure as an incidence rate; the model controlled for average age, percentage male, forecasted risk score (generated from prior use patterns), and deductible benefit design characteristics of the population for each annual evaluation period.

The study was found to be not human subjects research by Dartmouth College (CPHS \# STUDY00030530).

\section{RESULTS}

Over the 4-year period, all spine care costs decreased for both the intervention and the control group; however, those costs decreased at about 4 times the rate in the intervention group than the control group ( $28.3 \%$ vs. $7.2 \%$ reductions); most of the reduction in PMPM cost for spine care in the intervention group was attributable to reduced PMPM spine surgery costs (both $p<0.001$, Table 1). In both groups, opioid treatment PMPM costs and manual care PMPM costs increased from baseline. However, Poisson longitudinal regression results indicated that adjusted PMPM care costs in the intervention group fell, relative to those for the control group, for all examined categories save manual care, which increased at a statistically significant rate (Table 2).

\section{DISCUSSION}

In this retrospective, controlled, before-after study, we found that implementation of a conservative spine pain treatment pathway was associated with significant reductions in PMPM healthcare expenditures for spine pain care; most cost savings were attributable to reduction in spine surgery costs. Our Poisson model found relatively reduced opioid utilization and relatively increased manual care costs, both anticipated by-products of guideline implementation. ${ }^{4}$

While our findings are preliminary, in an era of increasing healthcare costs and use of complex and expensive spine surgery techniques they show promise for meaningful care cost reduction and value enhancement when providers 
Table 1 Mean, Adjusted Per-Member-Per-Month Expenditures for Spine Care Patients in the Intervention and Control Groups for Baseline Through Year 3, and Percentage Change from Baseline to Year 3, for Four Categories of Care: All Care, Spine Surgery Care, Opioids, and Manual Care. Percent Changes from Baseline Are Statistically Significant at $\boldsymbol{p}<0.001$

\begin{tabular}{lllllll}
\hline \hline Care category & Group & \multicolumn{2}{l}{ Per-member-per-month expenditures } & & \multicolumn{2}{c}{$\begin{array}{c}\text { Percentage change from } \\
\text { baseline to Year 3 }(\%)\end{array}$} \\
\cline { 3 - 6 } & & Baseline & Year 1 & Year 2 & Year 3 & \\
\hline All spine care & Intervention & $\$ 24.61$ & $\$ 21.35$ & $\$ 19.57$ & $\$ 17.64$ & -28.3 \\
Spine surgery & Control & $\$ 22.13$ & $\$ 23.80$ & $\$ 20.05$ & $\$ 20.55$ & -7.2 \\
& Intervention & $\$ 8.89$ & $\$ 7.08$ & $\$ 5.86$ & $\$ 5.01$ & -43.6 \\
Opioid treatment & Control & $\$ 6.78$ & $\$ 9.86$ & $\$ 6.21$ & $\$ 6.84$ & 0.01 \\
& Intervention & $\$ 1.46$ & $\$ 1.81$ & $\$ 1.94$ & $\$ 1.92$ & 31.5 \\
Manual care & Control & $\$ 1.17$ & $\$ 2.21$ & $\$ 1.53$ & $\$ 1.42$ & 21.4 \\
& Intervention & $\$ 3.91$ & $\$ 4.24$ & $\$ 4.48$ & $\$ 4.28$ & 9.5 \\
& Control & $\$ 3.79$ & $\$ 3.97$ & $\$ 4.43$ & $\$ 4.53$ & 19.5 \\
\hline
\end{tabular}

Table 2 Poisson Regression Time-Group Interaction Estimates and $p$ Values for Each Cost Category Examined. Negative Values Indicate a Relative Reduction in Per-Member-Per-Month Expenditures in the Intervention Group

\begin{tabular}{lll}
\hline \hline Care category & Time-group interaction estimate & $\boldsymbol{p}$ value \\
\hline All spine care & -0.1266 & $<0.0001$ \\
Spine surgery & -0.1899 & $<0.0001$ \\
Opioid treatment & -0.4387 & $<0.0001$ \\
Manual care & 0.0315 & $<0.0001$ \\
\hline
\end{tabular}

conservatively manage spine pain. Importantly, our analysis underscores the value of using control groups, formal analytics, and academic partnerships to understand the impact of quality improvement and clinical effectiveness projects, measures that have been recommended to improve the robustness of quality improvement efforts. ${ }^{5}$

Corresponding Author: William B. Weeks, MD, $P h D, M B A$; The Dartmouth Institute for Health Policy and Clinical Practice, Lebanon, NH, USA

\section{Compliance with Ethical Standards:}

Conflict of Interest: Dr. Pike, Mr. Donath, and Dr. Justice are employees of Excellus BlueCross BlueShield in Rochester, NY. Dr. Fiacco is an employee of Central New York Family Care, Syracuse, NY. Dr. Weeks declares that he has no conflict of interest.

\section{REFERENCES}

1. Mafi JN, McCarthy EP, Davis RB, Landon BE. Worsening trends in the management and treatment of back pain. JAMA Intern Med. 2013;173:1573-81.

2. Gaseem A, Wilt TJ, McLean RM, Forciea MA Noninvasive Treatments for Acute, Subacute, and Chronic Low Back Pain: A Clinical Practice Guideline From the American College of Physicians. Ann Intern Med. 2017;166:514-30.

3. Choosing Wisely: Treating lower-back pain. 2018. (http://www.choosingwisely. org/patient-resources/low-back-pain, Accessed January 10, 2019).

4. Weeks WB, Goertz CM. Ineffective Policies to Address the Opioid Epidemic. JAMA Psychiatry. 2017;74:974.

5. Grady D, Redberg RF, O'Malley PG. Quality Improvement for Quality Improvement Studies. JAMA Intern Med. 2018; 178(2): 187.

Publisher's Note Springer Nature remains neutral with regard to jurisdictional claims in published maps and institutional affiliations. 